\title{
PENENTUAN TOTAL FENOLIK DAN AKTIVITAS ANTIOKSIDAN FRAKSI ETIL ASETAT DARI TEPUNG PELEPAH AREN (Arenga pinnata)
}

\author{
Yudhie E. Prasetyo ${ }^{1)}$, Meiske S. Sangi ${ }^{1)}$, Audy D. Wuntu ${ }^{1)}$ \\ ${ }^{1)}$ Program Studi Kimia, FMIPA, Universitas Sam Ratulangi, Manado \\ Email: pointerzyudhie@gmail.com, meiskesangi@gmail.com, dennywuntu@yahoo.com
}

\begin{abstract}
ABSTRAK
Tujuan penelitian ini untuk menentukan total fenolik dan aktivitas antioksidan fraksi etil asetat dari tepung pelepah aren (Arenga pinnata). Tepung pelepah aren diekstraksi maserasi menggunakan etanol hasil redestilasi cap tikus kemudian di partisi menggunakan pelarut petroleum eter, etil asetat dan aquades. Penentuan kandungan total fenolik menggunakan metode Folin-Ciocalteu dan aktivitas antioksidan menggunakan metode serapan radikal 1,1-difenil-2pikrilhidrazil (DPPH). Didapati kandungan total fenolik fraksi etil asetat sebesar $172.857 \pm 4.762$ $\mathrm{mg} / \mathrm{kg}$ dan aktivitas penangkal radikal bebas fraksi etil asetat sebesar $90.573 \mu \mathrm{g} / \mathrm{mL}$. Hasil ini menunjukan bahwa fraksi etil asetat berpotensi sebagai antioksidan alami.
\end{abstract}

Kata kunci: Tepung Pelepah aren, fenolik, aktivitas antioksidan, DPPH

\section{DETERMINATION TOTAL PHENOLIC CONTENT AND ANTIOXIDANT ACTIVITY ETHYL ACETATE FRACTION OF AREN'S MIDRIB POWDER (Arenga pinnata)}

\begin{abstract}
This research aims to determine the total phenolic content and antioxidant activity from ethyl acetate fraction of Aren's midrib powder (Arenga pinnata). Aren's midrib powder extracted with maceration method with cap tikus redistillated ethanol and then partitioned with solvents such as petroleum ether, ethyl acetate and distillate water. The determination of phenolic content was using Folin-Ciocalteu method and the antioxidant activity was done using diphenylpycrylhydrazyl (DPPH) radical scavenging. Total phenolic value of ethyl acetate fraction is $172.857 \pm 4.762$ and $\mathrm{IC}_{50}$ value of ethyl acetate fraction is $90.573 \mu \mathrm{g} / \mathrm{mL}$. This result shows ethyl acetate fraction as natural antioxidant potential.
\end{abstract}

Keywords: Aren's midrib powder, phenolic, antioxidant activity, DPPH

\section{PENDAHULUAN}

Aren (Arenga pinnata) merupakan salah satu jenis tumbuhan tropis yang tersebar luas di Indonesia dan menjadi salah satu sumber kekayaan yang ada. Aren sangat bermanfaat dalam kehidupan, hampir setiap bagian dapat dimanfaatkan, seperti air nira hasil sadapan dapat dijadikan sebagai bahan utama pembuatan minuman beralkohol dan gula aren, buahnya dapat dijadikan sebagai kolang-kaling, ijuk dijadikan sebagai bahan dasar sapu ijuk dan tulang pada daun digunakan sebagai bahan dasar sapu lidi oleh masyarakat sekitar (Hatta, 1993).
Pelepah aren adanya serbuk halus yang digunakan masyarakat Minahasa sebagai obat gatal saat bekerja di kebun, masyarakat Sunda menggunakan abu pelepah daun aren yang telah dibakar sebagai bahan kosmetik tradisional untuk menghilangkan jerawat dan masyarakat Tomohon menjadikan tepung dari pelepah daun aren sebagai obat luka bakar dan gatal-gatal pada kulit (Sangi et al., 2012). Zainudin et al. (2015) melaporkan bahwa ekstrak akar aren mengandung senyawa metabolit sekunder, yaitu flavonoid, alkaloid, steroid/triterpenoid, tanin, saponin, terpenoid, antrakuinon. Sangi et al. (2012), melaporkan bahwa tepung 
pelepah daun aren mengandung senyawa fitokimia alkaloid, tannin, triterpenoid.

Berdasarkan uraian diatas, pelepah aren mengandung senyawa metabolit sekunder yaitu tanin, fenolik dan flavonoid, yang merupakan senyawa yang berperan sebagai antioksidan. Sehingga penelitian ini bertujuan untuk menentukan kandungan total fenolik dan aktivitas antioksidan dari ekstrak fraksi petroleum eter dan fraksi etil asetat tepung pelepah aren.

\section{METODE PENELITIAN}

\section{Bahan dan Alat}

Bahan yang digunakan adalah tepung pelepah aren yang diambil dari desa Karor, kabupaten Minahasa. Bahan kimia yang digunakan adalah etanol (teknis dan p.a), petroleum eter p.a, etil asetat p.a, aquades, $\mathrm{Na}_{2} \mathrm{CO}_{3}$, reagen Folin Ciocalteu dan 1,1difenil-2-dipikrilhidrazil (DPPH). Peralatan yang digunakan adalah alat-alat gelas pyrex, corong pisah, Erlenmeyer, kertas saring, rotary evaporator, desikator, sudip, batang pengaduk, mikropipet, UV-Vis Shimadzu.

\section{Preparasi Sampel}

Pelepah aren yang sudah tua dan kering dibersihkan, dipotong secara vertikal dan diambil bagian dalamnya berupa tepung halus kemudian diayak. Selanjutnya disimpan dalam wadah untuk analisa lebih lanjut.

\section{Penentuan Kadar Air}

Kadar air ditentukan menggunakan metode pemanasan oven. Tepung pelepah aren diambil secukupnya lalu ditimbang. Setelah itu, dipanaskan dalam oven pada suhu $105^{\circ} \mathrm{C}$ selama 3 jam. Didinginkan dalam desikator selama 30 menit, lalu ditimbang. Kemudian dipanaskan dan didinginkan kembali hingga mencapai berat konstan. Persentasi kadar air dihitung menggunakan persamaan berikut.

$$
\% \text { Kadar air }=\frac{\text { berat awal }- \text { berat akhir }}{\text { berat awal }} \times 100 \%
$$

\section{Ekstraksi dan Partisi}

Sebanyak $1.5 \mathrm{~kg}$ tepung pelepah daun aren dimaserasi menggunakan etanol hasil redestilasi cap tikus selama $2 \times 24$ jam, disaring kemudian dipekatkan menggunakan rotary evaporator. Ekstrak etanol yang diperoleh kemudian disimpan lalu dilanjutkan pada tahap partisi.

Sebanyak 5 gr ekstrak etanol awal dilarutkan dalam $50 \mathrm{~mL}$ aquades. Larutan selanjutnya dipartisi dengan menambahkan $100 \mathrm{~mL}$ pelarut petroleum eter, dikocok dalam corong pisah dan didiamkan selama 10-15 menit hingga terdapat dua lapisan (petroleum eter pada lapisan atas dan aquades pada lapisan bawah). Diambil lapisan petroleum eter. Dilakukan beberapa kali hingga lapisan petroleum eter terlihat bening. Lapisan aquades difraksinasi kembali dengan cara yang sama menggunakan pelarut etil asetat. Hasil fraksinasi diuapkan menggunakan rotary evaporator sehingga didapati fraksi petroleum eter, fraksi etil asetat dan Fraksi air.

\section{Penentuan Kandungan Total fenolik}

Sebanyak $0.1 \mathrm{~mL}$ fraksi etil asetat ditambahkan $0.1 \mathrm{~mL}$ reagen Folin-Ciocalteu lalu divortex. Setelah itu ditambahkan $2 \mathrm{~mL}$ $\mathrm{Na}_{2} \mathrm{CO}_{3} \quad 2 \%$ lalu divortex kembali. Selanjutnya diinkubasi pada ruangan gelap selama 30 menit. Absorbansi diukur menggunakan spektrofotometer UV-Vis pada panjang gelombang $750 \mathrm{~nm}$.

\section{Uji Aktivitas Antioksidan dengan Metode DPPH}

Sebanyak $0.5 \mathrm{~mL}$ larutan fraksi etil asetat dengan berbagai konsentrasi (1000, $2000, \quad 3000, \quad 4000$ dan $5000 \mu \mathrm{g} / \mathrm{mL}$ ) ditambahkan $1.5 \mathrm{~mL}$ larutan 1,1-difenil-2pikrilhidrazil (DPPH), divortex dan dimasukkan pada ruangan tertutup selama 30 menit. Dibaca absorbansinya pada panjang gelombang $517 \mathrm{~nm}$. Kemudian dihitung persentasi penangkal radikal bebasnya. Dari persentasi penangkal radikal bebas dengan konsentrasi larutan uji, dibuat persamaan regresi linier untuk menentukan nilai $\mathrm{IC}_{50}$. Dibuat vitamin $\mathrm{C}$ pada berbagai konsentrasi $(10,20,30,40$ dan $50 \mu \mathrm{g} / \mathrm{mL})$ sebagai pembanding. Adapun aktivitas penangkal radikal bebas DPPH dihitung sebagai presentasi berkurangnya warna DPPH dengan menggunakan persamaan berikut.

Aktivitas penangkap radikal bebas (\%)

$$
=1-\frac{\text { Absorbansi Sampel }}{\text { Absorbansi kontrol }} \times 100 \%
$$




\section{HASIL DAN PEMBAHASAN}

\section{Kadar Air Tepung Pelepah Aren}

Penentuan kadar air dari tepung pelepah aren dilakukan untuk mengetahui banyaknya kandungan air yang terkandung. Persentasi kadar air tepung pelepah aren sebesar $7.116 \%$. Penentuan kadar air bermanfaat untuk mengetahui ketahanan suatu bahan dalam penyimpanannya dan merupakan cara penanganan terbaik untuk menghindari pengaruh Aktivitas mikroorganisme. Jumlah kadar air yang rendah membuat bahan akan lebih lama disimpan dalam jangka waktu yang relatif lama sehingga kemungkinan rusak saat penyimpanan sangat kecil.

\section{Ekstraksi dan Partisi}

Ekstraksi tepung pelepah aren digunakan teknik maserasi, yang merupakan ekstraksi sederhana karena dilakukan dengan cara perendaman serbuk simplisia dalam pelarut pada suhu ruang. Pelarut akan menembus dinding sel dan akan melarutkan zat aktif didalamnya karena adanya perbedaan konsentrasi sehingga larutan yang terpekat akan didesak keluar. Hasil yang diperoleh rendemen sekitar $0.605 \%$ dengan berat ekstrak 9.074 gr dan berwarna coklat tua. Pelarut yang digunakan dalam ekstraksi adalah etanol. Etanol merupakan pelarut polar dan merupakan pelarut yang baik untuk ekstraksi karena dapat mengekstrak senyawasenyawa polar dan non polar. Hal ini dikarenakan adanya gugus hidroksil $(-\mathrm{OH})$ yang bersifat polar dan gugus alkil $\left(-\mathrm{CH}_{2}-\right.$ $\mathrm{CH}_{3}$ ) yang bersifat non polar (Harborne, 1987).

Partisi pada tepung pelepah aren bertujuan untuk memisahkan senyawa berdasarkan kelarutannya terhadap pelarut dengan tingkat kepolaran yang berbeda-beda seperti prinsip like dissolve like. Senyawa non-polar akan dilarutkan oleh pelarut petroleum eter, senyawa bersifat semi polar akan terekstrak pada pelarut etil asetat dan senyawa yang polar akan larut pada pelarut air. Hasil partisi dari tepung pelepah aren diperoleh tiga fraksi, yaitu fraksi petroleum eter, fraksi etil asetat dan fraksi air (lihat Tabel 1).
Tabel 1. Rendemen hasil fraksi tepung pelepah aren

\begin{tabular}{ccc}
\hline Fraksi & $\begin{array}{c}\text { Rendemen } \\
(\boldsymbol{\%})\end{array}$ & Warna \\
\hline PE & 22.768 & Coklat tua \\
EA & 10.944 & Coklat \\
Air & 50.962 & Coklat \\
\hline
\end{tabular}

Berdasarkan data pada Tabel 1, terlihat jelas bahwa fraksi Air mempunyai rendemen tertinggi kemudian diikuti fraksi PE dan fraksi EA. Banyaknya rendemen fraksi air disebabkan banyaknya jumlah senyawa polar yang terkandung dalam tepung pelepah aren dan tingginya rendemen pada fraksi PE diindikasikan adanya lemak atau minyak yang terkandung dalam pelepah aren.

\section{Penentuan Kandungan Total Fenolik}

Uji kandungan total fenolik dengan metode Folin-Ciocalteu bertujuan untuk mengetahui jumlah fenol yang terdapat pada sampel uji. Metode ini didasarkan pada kemampuan ekstrak untuk mereduksi reagen Folin-Ciocalteu yang mengandung senyawa fosfomolibdat-fosfotungstat. Reagen FolinCiocalteu adalah pereaksi anorganik yang dapat membentuk larutan kompleks dengan senyawa fenol, yakni senyawa molibdenum tungstat yang berwarna biru, dimana semakin pekat intensitas warna menunjukkan kandungan fenol semakin besar (JulkunenTitto, 1985). Reaksi antara reagen FolinCiocalteu dan fenol dapat dilihat sebagai berikut.

$$
\begin{gathered}
\mathrm{Na}_{2} \mathrm{WO}_{4} / \mathrm{Na}_{2} \mathrm{MoO}_{4}+\text { Fenol } \longrightarrow\left(\text { Fenol-MoW } \mathrm{MoO}_{11} \mathrm{O}_{40}\right)^{-4} \\
\mathrm{Mo}(\mathrm{VI})_{(\text {kuning })}+\mathrm{e}^{-} \longrightarrow \mathrm{Mo}(\mathrm{V})_{(\text {biru })}
\end{gathered}
$$

Metode Folin tidak membedakan antar jenis komponen fenolik. Semakin banyak jumlah gugus hidroksi fenolik, maka semakin besar konsentrasi komponen fenolik yang terdeteksi (Khadambi, 2007). Menurut Singleton \& Rossi (1965), warna biru yang teramati berbanding lurus dengan konsentrasi ion fenolat yang terbentuk, semakin banyak ion fenolat yang terbentuk sehingg warna biru yang dihasilkan semakin pekat.

Kandungan total fenolik yang terdapat pada fraksi etil asetat sebesar $172.857 \pm 4.762 \mathrm{mg} / \mathrm{kg}$. Konsentrasi yang diperoleh dari persamaan kurva standar asam 
galat $y=0.0049 x+0.0605$. Senyawa fenol berpotensi sebagai antioksidan karena disebabkan oleh keberadaan gugus hidroksil $(-\mathrm{OH})$ yang berfungsi sebagai penyumbang elektron. Menurut Tursiman et al. (2012), pada umumnya senyawa yang memiliki bioaktivitas sebagai antioksidan adalah senyawa golongan fenol yang memiliki gugus hidroksi yang tersubtitusi pada cincin benzena pada posisi orto dan para terhadap gugus $-\mathrm{OH}$ dan $-\mathrm{OR}$. Senyawa ini dapat menghambat radikal bebas dengan mendonorkan protonnya dan membentuk radikal stabil. Terbentuknya radikal stabil ini dikarenakan elektron bebas distabilkan oleh delokalisasi elektron dengan adanya resonansi pada cincin aromatik.

\section{Penentuan Aktivitas Antioksidan dengan Metode DPPH}

Pengujian aktivitas antioksidan menggunakan radikal bebas DPPH sebagai media pengujian. Pengujian aktivitas penangkal radikal bebas dilakukan dengan mereaksikan larutan uji dengan larutan DPPH dan dibaca absorbansinya pada panjang gelombang $517 \mathrm{~nm}$. Penurunan intensitas warna larutan DPPH sebagai akibat terjadi pelepasan atom hidrogen dari senyawa fenolik kepada senyawa DPPH yang kekurangan elektron.

Gambar 1 menunjukan aktivitas penangkal radikal bebas DPPH dari fraksi etil asetat, semakin tinggi konsentrasi dari sampel uji, semakin tinggi pula aktivitas antioksidannya. Rice-Evan et al. (1997), melaporkan bahwa aktivitas antioksidan dan fitokimia yang berasal dari tanaman sebanding dengan kandungan fenolik, yang berarti semakin banyaknya komponen fenolik (fenolik, flavonoid dan tanin terkondensasi), semakin besar aktivitas antioksidannya.

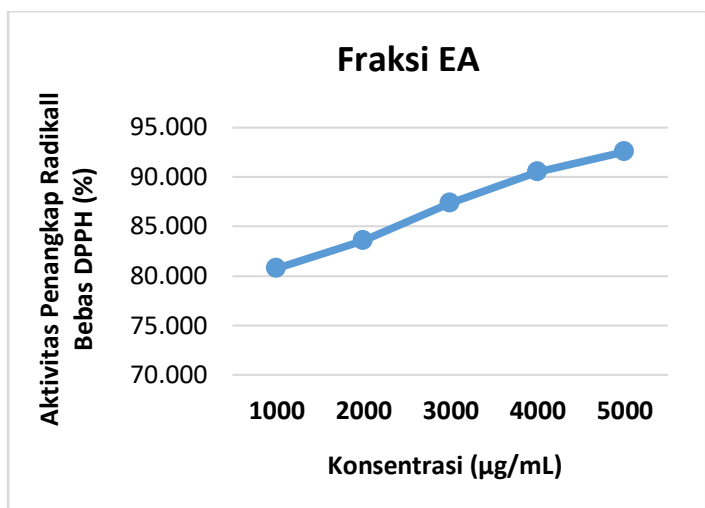

Gambar 1. Aktivitas penangkal radikal bebas fraksi etil asetat

Fraksi etil asetat memiliki kemampuan sebagai penangkal radikal bebas DPPH lebih besar 50\%. Komponen senyawa pada fraksi etil asetat lebih aktif dalam melepaskan atau mendonorkan atom hydrogen atau elektron kepada radikal DPPH (ungu) menjadi senyawa non radikal (kuning) (Molyeux, 2004). Reaksi utamanya dapat dilihat pada Gambar 2.

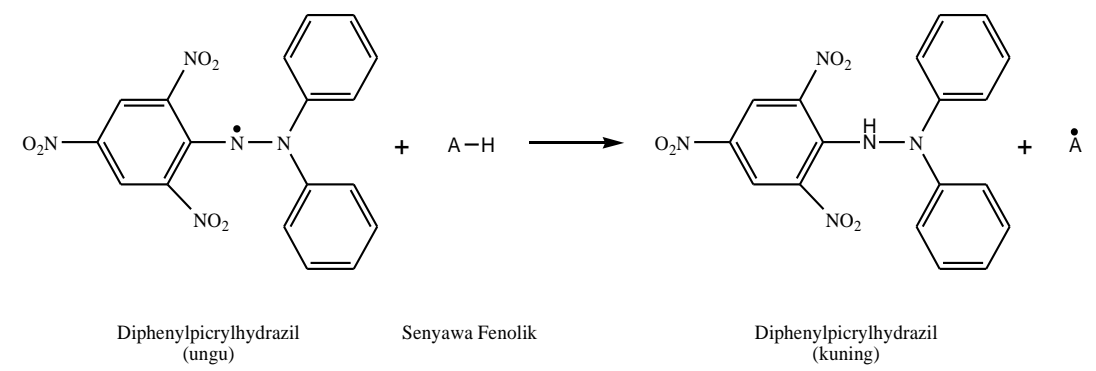

Gambar 2. Reaksi penangkap radikal bebas (AH) denga DPPH (Molyneux, 2004)

Dibuat kurva persamaan regresi antara persen penangkal radikal bebas terhadap konsentrasi larutan uji untuk menentukan nilai $\mathrm{IC}_{50}$. Pada persamaan regresi yang didapat, y diisi dengan nilai 50 sehingga didapati nilai x yang disajikan pada tabel 2 .
Tabel 2. Perbandingan $\mathrm{IC}_{50}$ fraksi etil asetat dan Vit. C

\begin{tabular}{|c|c|c|c|}
\hline $\begin{array}{c}\text { Sampel } \\
\text { Uji }\end{array}$ & $\begin{array}{c}\text { Persamaan } \\
\text { Regresi }\end{array}$ & $\mathbf{R}^{2}$ & $\begin{array}{l}\text { Nilai } \\
\text { IC }_{50}\end{array}$ \\
\hline $\begin{array}{l}\text { Fraksi } \\
\text { EA }\end{array}$ & $\begin{array}{c}y=25.179 x+ \\
0.7151\end{array}$ & 0.9962 & 90.573 \\
\hline $\begin{array}{c}\text { Vitamin } \\
\mathrm{C}\end{array}$ & $\begin{array}{c}y=1.6757 x- \\
1.1281\end{array}$ & 0.9851 & 30.511 \\
\hline
\end{tabular}


Parameter atau perhitungan yang digunakan dalam penentuan aktivitas penangkal radikal bebas adalah $\mathrm{IC}_{50}$. Nilai tersebut menggambarkan besarnya konsentrasi larutan uji yang dapat menangkal radikal sebesar $50 \%$ dan atau menyebabkan $50 \%$ DPPH kehilangan karakter radikal. Semakin nilai $\mathrm{IC}_{50}$, menunjukkan senyawa uji tersebut akan semakin efektif sebagai penangkap radikal (Molyneux, 2004).

Vitamin $\mathrm{C}$ yang digunakan sebagai pembanding memiliki nilai $\mathrm{IC}_{50}$ sebesar $30.511 \mu \mathrm{g} / \mathrm{mL}$. Vitamin $\mathrm{C}$ memiliki nilai $\mathrm{IC}_{50}$ yang lebih kecil dibandingkan dengan fraksi etil asetat. Jika dibandingkan dengan nilai $\mathrm{IC}_{50}$ dari fraksi etil asetat dan vitamin $\mathrm{C}$, senyawa dari fraksi etil asetat cukup berpotensi sebagai antioksidan. Vitamin $\mathrm{C}$ memiliki aktivitas antioksidan yang tinggi karena memiliki dua gugus hidroksil yang dapat mendonorkan atom hidrogen untuk menstabilkan radikal bebas (Sudarmadji, 1996).

\section{KESIMPULAN}

Kandungan total fenolik fraksi etil asetat tepung pelepah aren (Arenga pinnata) sebesar $172.857 \pm 4.762 \mathrm{mg} / \mathrm{kg}$. Aktivitas antioksidan fraksi etil asetat sebesar 90.573 $\mu \mathrm{g} / \mathrm{mL}$. Fraksi etil asetat berpotensi sebagai antioksidan alami.

\section{DAFTAR PUSTAKA}

Harborne, J. B. 1987. Metode Fitokimia. Terjemahan: Padmawinata, K. \& I. Soediro. ITB. Bandung.

Hatta, S. 1993. Aren Budidaya dan Multigunanya. Kanisius. Yogyakarta.

Julkunen-Titto, R. 1985. Phenolic Constituents in Leaves of Northern Willows: Method for Analysis of Certain Phenolic. J. Agric. Food Chem. 33: 22-23
Khadambi, T. N. 2007. Extraction of Phenolic Compounds and Quantification of The Total Phenol and Condensed Tannin Content of Bran Fraction of Condensed Tannin and Condensed Tannin Free Sorghum Varieties. University of Pretoria. Pretoria.

Molyneux, P. 2004. The Use of Stable Free Radical Diphenylpicrylhidrazil (DPPH) for Estimating Antioxidant Activity. J. Sci. Technol. 26: 211219

Rice-Evan, C. A., N. J. Miller \& Paganga. 1997. Antioxidant Properties of Phenolic Compounds. Trend. Plant Sci. 2: $152-159$

Sangi, M., L. Momuat \& M. Kumaunang. 2012. Uji Toksisitas dan Skrining Fitokimia Tepung Gabah pelepah Aren (Arenga pinnata). Jurnal Ilmiah Sains. 12(2): 128-134

Singleton, V. L. \& J. A. Rossi. 1965. Colorimetry of Total Phenolic with Phosphomolybdic-Phosphotungstic Acid Reagent. American Journal Enology and Viticulture. 16:147.

Sudarmadji, S., B. Haryono \& Suhardi. 1996. Analisa Bahan Makanan dan Pertanian. Liberty. Yogyakarta.

Tursiman, P. Ardiningsih \& R. Nofiani. Total Fenol Fraksi Etil Asetat dari Buah Asam Kandis (Garcinia dioica Blume). JKK. 1(1): 45-48.

Zainudin, A., U. Hasanah \& Y. R. Pemana. 2015. Uji Aktivitas Diuretik Ekstrak Akar Aren (Arenga pinnata Merr.) Terhadap Tikus Putih Galur Wistar (Rattus norvgicus) dengan Pembanding Furosemid. Jurnal Kesehatan Prima. 9(1):1403-1411 